\title{
A new concept for the safety of low-lying land areas from natural disasters
}

\author{
Toshio Nakajima $\cdot$ Motohiko Umeyama
}

Received: 25 March 2014 / Accepted: 10 July 2014 / Published online: 5 September 2014

(C) Springer International Publishing AG 2014

\begin{abstract}
We introduce a new concept that utilizes floating foundations to create an urban community base in manmade inlets and basins - an idea that enables the attainment of a prosperous and sustainable urban and rural environment in the long term. This paper proposes the establishment of secure bases using a floating structure to safeguard from natural disasters, especially from flooding caused by heavy rain, storm surges caused by typhoons, tsunamis, and earthquakes. In addition, we introduce a plan for the reconstruction of an area in northeast Japan destroyed by the Great East Japan Earthquake.
\end{abstract}

Keywords Sustainable $\cdot$ City planning $\cdot$ Natural disasters . Flooding $\cdot$ Lower-lying land areas

\section{Introduction}

On March 11, 2011, unprecedented disasters hit the shores of northeast Japan because of a massive tsunami caused by a huge undersea earthquake. The strongest breakwater, $10 \mathrm{~m}$ high, was destroyed completely. The valuable lesson learned from this experience is that it is impossible to protect ourselves from such extraordinary natural disasters by mere construction of massive civil engineering structures such as seawalls and breakwaters. In addition, urban seawalls and dikes in many locations are suffering erosion damage, and their replacement or reinforcement is becoming necessary despite the prohibitive costs involved. When considering the inevitable rise in sea levels in the long term, the height of sea-

T. Nakajima · M. Umeyama $(\bowtie)$ Department of Civil and Environmental Engineering, Tokyo

Metropolitan University, 1-1 Minamiohsawa, Hachioji,

Tokyo 192-0397, Japan

e-mail: umeyama-motohiko@tmu.ac.jp walls must also keep rising. However, proposing to replace or reinforce every seawall in Japan is unrealistic. Public funds are limited, whereas the costs associated with infrastructure replacement or reinforcement are unlimited.

On the other hand, we cannot ignore the likelihood that the magnitude of natural disasters will annually increase because of future climatic changes. Some kind of countermeasures to safeguard the coastal and riverside areas are necessary to be introduced against water-related disasters for 50- or 100-year return period. It is vital to find alternative solutions that will produce a higher degree of safety through disaster mitigation. The Intergovernmental Panel on Climate Change (2014) (IPCC) estimates that average global temperatures will rise 2.6-4. ${ }^{\circ} \mathrm{C}$ by the year 2100 , relative to 1990 , and sea levels will rise $45-82 \mathrm{~cm}$. These study projections have existed for some decades. For instance, Titus and Narayanan (1995) concluded that there is a $1 \%$ chance that the global sea level could rise by more than $4 \mathrm{~m}$ over the next two centuries. Numerous investigations confirm that the indirect effects may be more significant than the direct effects from global warming in this century: rising sea levels inundate low-lying land areas, erode beaches, and increase the salinity of rivers and estuaries. Climate change also affects the frequency and intensity of some extreme phenomena. Bender et al. (2010) and Knutson et al. (2010) suggest that the extent and severity of storm impacts may increase as a result of regional climate changes. Recently, Umeyama (2012) reported that the abrupt phase shift of the El Nino Southern Oscillation has resulted in severe cyclones in the Southern Pacific. One example is the November 8, 2013, Typhoon Haiyan that destroyed about $70-80 \%$ of the structures in its path as it tore through Leyte province in the Philippines. A huge storm surge up to $5 \mathrm{~m}$ high surged inland and swept away coastal villages.

In recent years, strenuous efforts have been made to restore damage to the global environment and create a more sustain- 


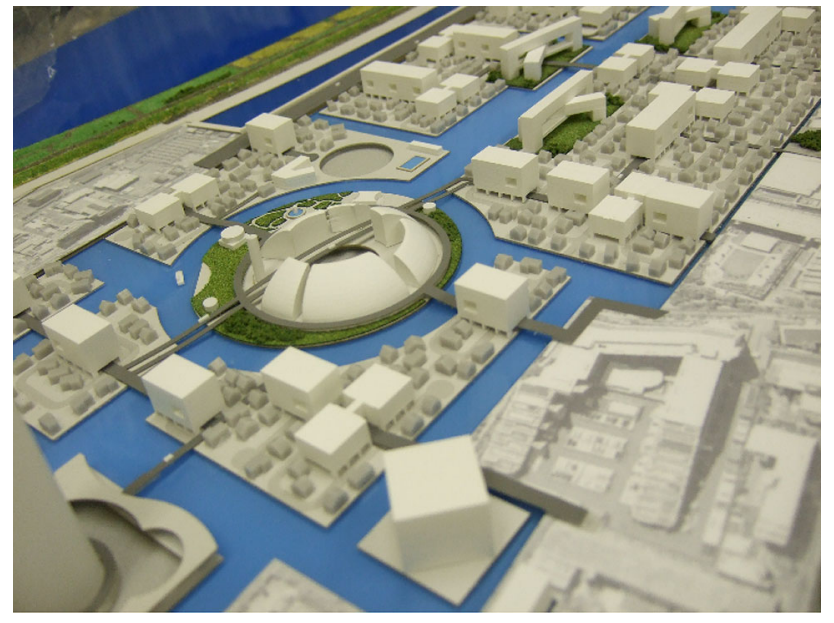

Fig. 1 Bird's-eye view of the "Water City" project

able society. Yet, in spite of the widespread movement to diminish greenhouse gases, substantial rewards are yet to be reaped. It may be impossible to halt the acceleration of sea level rise under the influence of global warming. The situation is dire for the many cities located near a river or sea. Moreover, many such cities are located below the water level along the sea. Therefore, there is an urgent need to devise and implement effective solutions for minimizing damage caused by natural disasters. The construction of social infrastructures capable of withstanding the impact of any global climate change must begin immediately. Residents of coastal areas must be alerted to be prepared for future disasters.

The authors propose that to deal with water-related disasters, as exemplified by floods, the answer lies not in massive structures like dams, dikes, and seawalls but rather in taking an indirect approach that tames the water's impact and minimizes the effect of water-related disasters more economically. Based on an image by Nakajima and Umeyama (2007) shown in Fig. 1, we continued to work and refine the more detailed studies (Nakajima et al. 2011, 2012; Nakajima and Umeyama 2013) on this subject.

\section{Considerations and objectives}

Urban redevelopment henceforth has as the main issue the bridling of construction costs while realizing things through simpler means. To achieve this, the idea of creating water areas to the widest extent possible for maximum utilization of sea and river waters as well as of natural precipitations came about. As for the higher-lying lands, these can be used for reforestation and food production that attract a diverse lot of living organisms. Actually, there seems to be limited recognition now that in general "the float" is useful in making the most of the inside space to be found within. But, furthermore, not only are the platforms safer with its inherent ability to "ride out" disasters, they are economically more sensible when viewed from the standpoint of resilience against natural disasters; when compared to land-based building structures that would require rebuilding from scratch in face of extensive damages, they are less likely to be damaged while being easier to replace. An example of a low-lying waterfront zone at sea level near an ocean and/or river is presented below. The plan is to change the potential danger in this location to produce an area safeguarded against abovementioned natural disasters. An outline of the process follows:

As a first step, an area approximately half of the size of this location is excavated to a depth of several meters and the topsoil removed. The topsoil removed from the location is to be relocated to raise the urban area above sea level. These are filled with freshwater and/or saltwater until the water level behind the levee reaches sea level, to bring forth a manmade inlet and/or basin. Finally, buildings are constructed on the floaters inside the man-made basin. Road bridges with flexible joints are built to enable travel between the floaters and the land. In general, the larger the area of water surface provided, the more comfortable the amenities will be.

A waterfront development in a low-lying urban area can be a flood prevention measure by itself because the target area is able to function as a subsidiary pool. In general, the water accumulated by precipitation over an integrated reservoir can be used for secondary human activities such as lavatory flushing and garden sprinklers. This additional water source can be used to supplement the city's existing drinking water and sewage systems.

Furthermore, other benefits arise from a water city in which all buildings are constructed on floating foundations. The city is made safe against a large earthquake as the water cushions structures from seismic shocks. Also, water is readily available for firefighting, and water required for domestic use is ensured even after a disaster.

The objectives of the waterfront construction are as follows:

1. An improved local living environment that enables citizens to comfortably enjoy the canals.

2. Flood prevention from the rivers due to future storm surge, tsunami, levee break, and sea-level rise.

3. Protection of the community from localized heavy rain caused by global climate change (especially in low ground areas).

4. An improved urban living environment by reducing the heat load of the city (a counter-measure for the "urban heat island" effect).

5. The replacement of automobiles with waterborne transportation.

6. The installation of biotopes for protecting aquatic organisms, thereby preserving the natural water environment.

7. The restoration of the water cycle system by filling the underground area with water (to maintain a water 
supply during periods of water shortage). Since rainwater in urban areas is also an important natural resource, rainwater will be stored to the highest degree possible. By facilitating the water's seepage underground after storage, we can realize a highly advanced society that circulates its water by utilizing wells and that can transform disasters, such as floods, into heaven-sent resources.

\section{Water CityProject for Koto Ward of Tokyo}

\subsection{Recent circumstances and problems in Tokyo}

For the past several decades, assisted by government investment in public works, urban construction of houses, apartments, and other buildings as well as urban infrastructure, such as roads and railways, has been unabated. These projects have been carried out with the purpose of encouraging economic expansion while meeting the demands of rapid growth both in terms of Japan's population and economy. There is now a movement against policies promoting ill-considered construction projects to make way for a more prosperous future. Looking a century or more into the future, the keyword for effective long-term urban construction projects and all other human endeavors is undoubtedly "sustainability." Cities must be built that not only withstand global environmental disasters but also sustain and protect the environment.

However, cities such as Tokyo and Osaka face waterrelated disasters caused by global climate change. Current water shortage arising from reduced rainfall during dry summers and flooding from concentrated heavy rain in restricted regions cannot be ignored. In many cases, flooding occurs in urban areas where the ground is covered with concrete and asphalt, preventing rainwater from seeping into the underlying soil and during dry periods, bringing about overheating called the "urban heat island" syndrome.

Furthermore, there is the danger of a massive and destructive earthquake hitting the Tokyo area in future. The biggest threat from earthquakes is the fire following a seismic disturbance. This was demonstrated by the Great Hanshin Earthquake of January 1995 and the Great East Japan Earthquake of March 2011. It was almost impossible to control the fire because of the damage caused by these earthquakes to the water station and the electric power station. Thereafter, the disaster refugees suffered from a shortage of fresh water for drinking, washing, and bathing. The lesson learned from these disasters is that supply of usable water is of the highest priority following a natural disaster.

\subsection{Outline of the project site}

To apply our concept for larger cities, we conducted a study of Koto Ward in Tokyo. Koto Ward is located in a low-lying

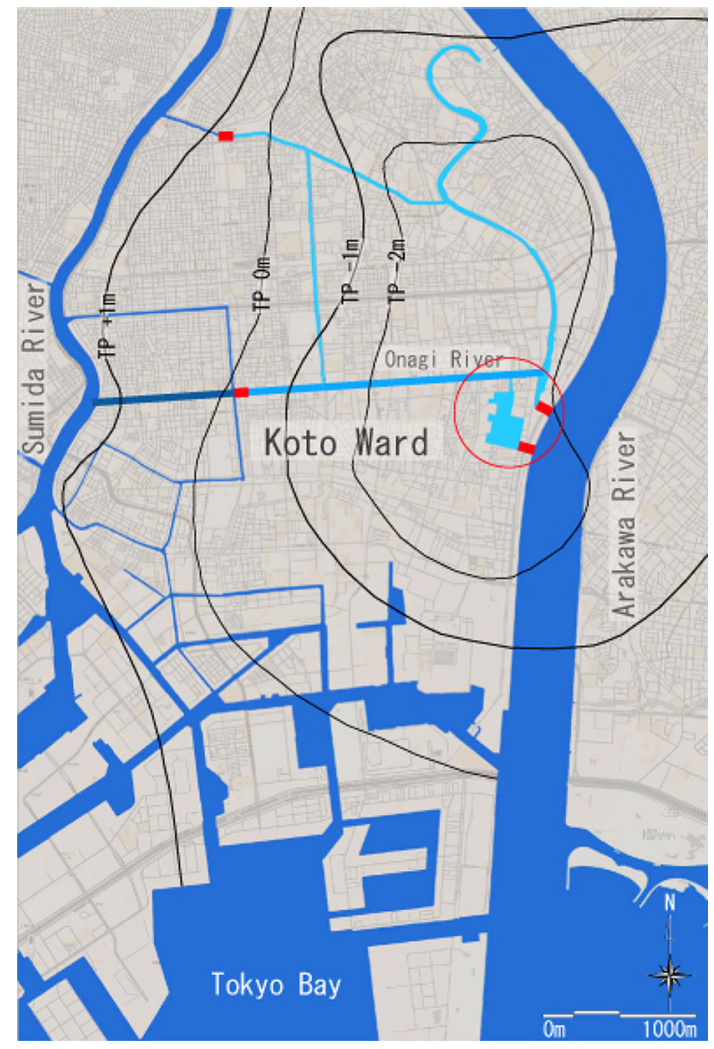

Fig. 2 Project site for Koto Ward, Tokyo

district called the Koto Triangle between the Sumida River and the Arakawa River and is bound by Tokyo Bay. The source of both rivers is Mount Kobushi, which has an elevation of 2,475 m. These rivers have gouged out the ground and led to the formation of valleys between steep mountains in the Okuchichibu region. The project site is located approximately $3 \mathrm{~km}$ from the Tokyo Bay.

Koto Ward used to be one of the most prosperous suburban industrial areas in Tokyo. However, the substantial quantities of underground water being pumped up through wells encouraged land subsidence. The situation has remained highly critical. Today, two-thirds of the total area of Koto Ward is lower than the average sea level of Tokyo Bay (see Fig. 2), and the area as a whole is protected by a number of water gates, levees, and seawalls. The project site is located in the eastern area of Koto Ward where the surface level of the water channels is adjusted to $2 \mathrm{~m}$ below the average surface level of the Arakawa River. Because the area faces a higher risk of flooding, Koto Ward depends heavily on tall levees (5 $\mathrm{m}$ or more above sea level). Boats in waterborne traffic travel between the Sumida River and Arakawa River through lock gates.

In late March 2006, Japan's Ministry of Land, Infrastructure and Transport investigated the safety of levees that had been constructed to protect Tokyo from flooding by the 


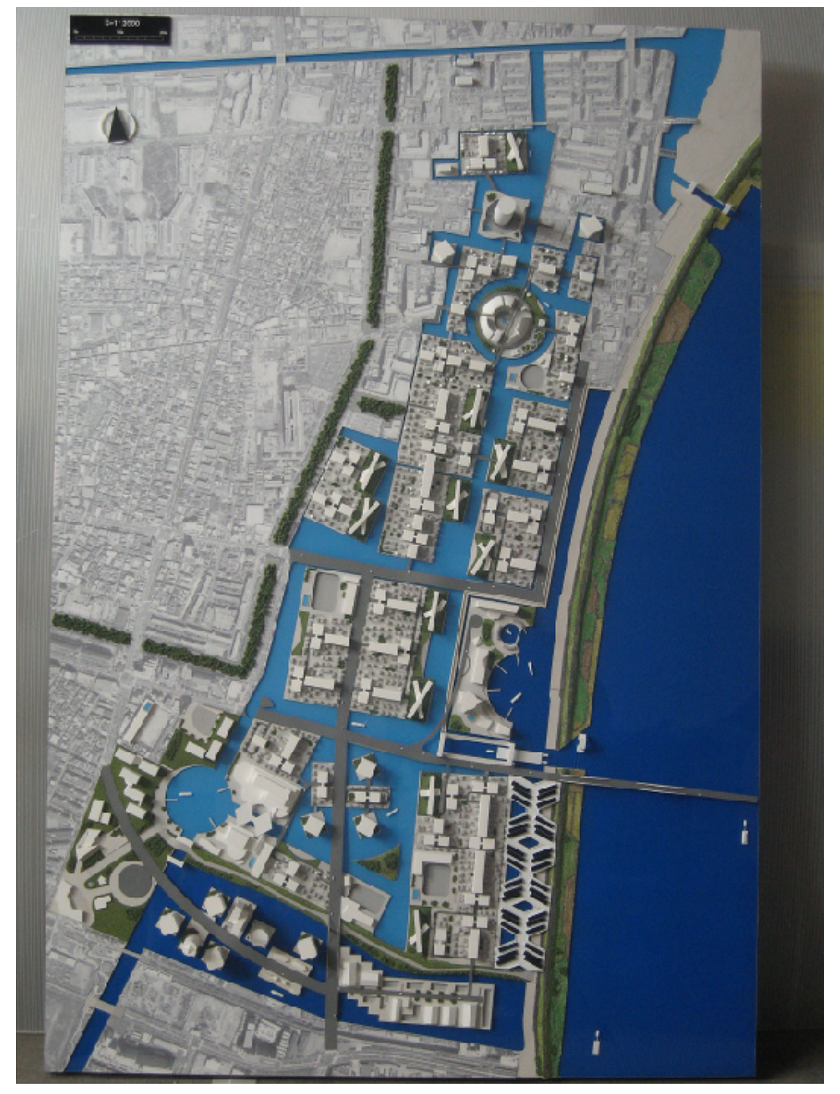

Fig. 3 Site plan of the redevelopment of Koto Ward

Arakawa River. The results revealed that safety standards were not being met over a distance of $123 \mathrm{~km} \mathrm{(58 \% )} \mathrm{out} \mathrm{of}$ the total $212 \mathrm{~km}$ of levees investigated because of the risk of "seepage failure" or the sudden levee collapse. The construction necessary to repair these levees is too extensive to be conceivable.

Meanwhile, private developers have been promoting condominium development in Koto Ward, thereby speeding up the demographic expansion. The population was 300,000 in 1957 , but was more than 487,000 in January of 2014. The total land area of Koto Ward is $39.9 \mathrm{~km}^{2}$, and its population density is 121.8 persons/ha. There are huge warehouses of logistics companies adjacent to private dwellings in residential areas. The project site in particular is characterized by random development-narrow and disorganized streets with a few parks. If a large earthquake or fire were to occur, the situation would become highly critical.

\subsection{Approach and urban redevelopment concept for Koto Ward}

The original city plan for Koto Ward by Nakajima and Umeyama (2009), shown in Fig. 3, covers a total area of approximately $1.25 \mathrm{~km}^{2}$, that is roughly $2 \mathrm{~km}$ from north
Table 1 Population, households and population density of the project site

\begin{tabular}{lll}
\hline Population & Households & Population density \\
\hline 27,500 persons & 12,600 & 223.6 person/ha \\
\hline
\end{tabular}

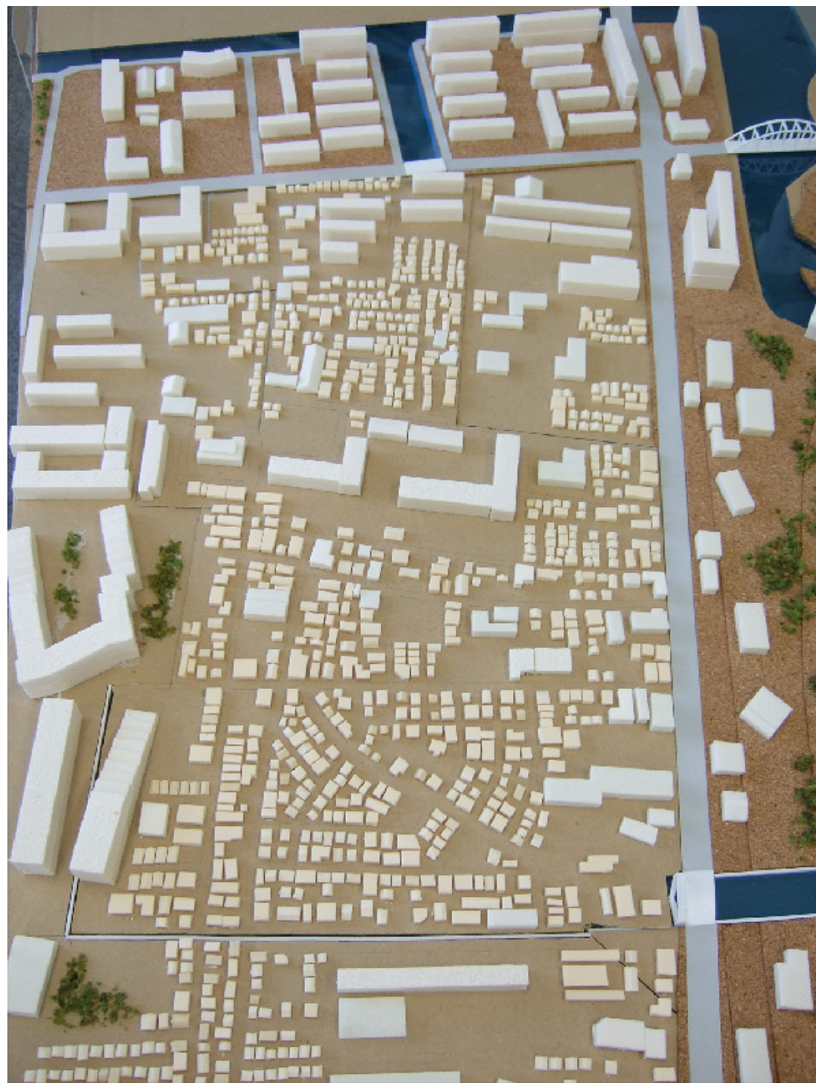

Fig. 4 Original condition of the project site

to south and between 0.5 and $1.0 \mathrm{~km}$ from east to west. The population, households and population density in this section are listed in Table 1. The plan includes the development of a mid- to- high-rise housing area (about 560 persons/ha) and a waterfront area as an open space that occupies nearly half the total area $\left(625,000\right.$ or $22.7 \mathrm{~m}^{2} /$ person $)$. The planned population, set at its current size (i.e., from 27,000 to 30,000 ), is three times that of neighboring communities (i.e., from 8,000 to 10,000 people).

The northern part of this site was designated as a residential area for which detailed engineering and economic studies were conducted by Nakajima and Umeyama (2010). Figure 4 shows the original condition of the project area with crowded, old low-rise connected wooden houses. A feasibility study for this site has been carried out based on our design concept, and the process is described as follows:

First, the area is excavated to a depth of $5 \mathrm{~m}$, and the topsoil is removed. The total area developed by excavating soil in this 


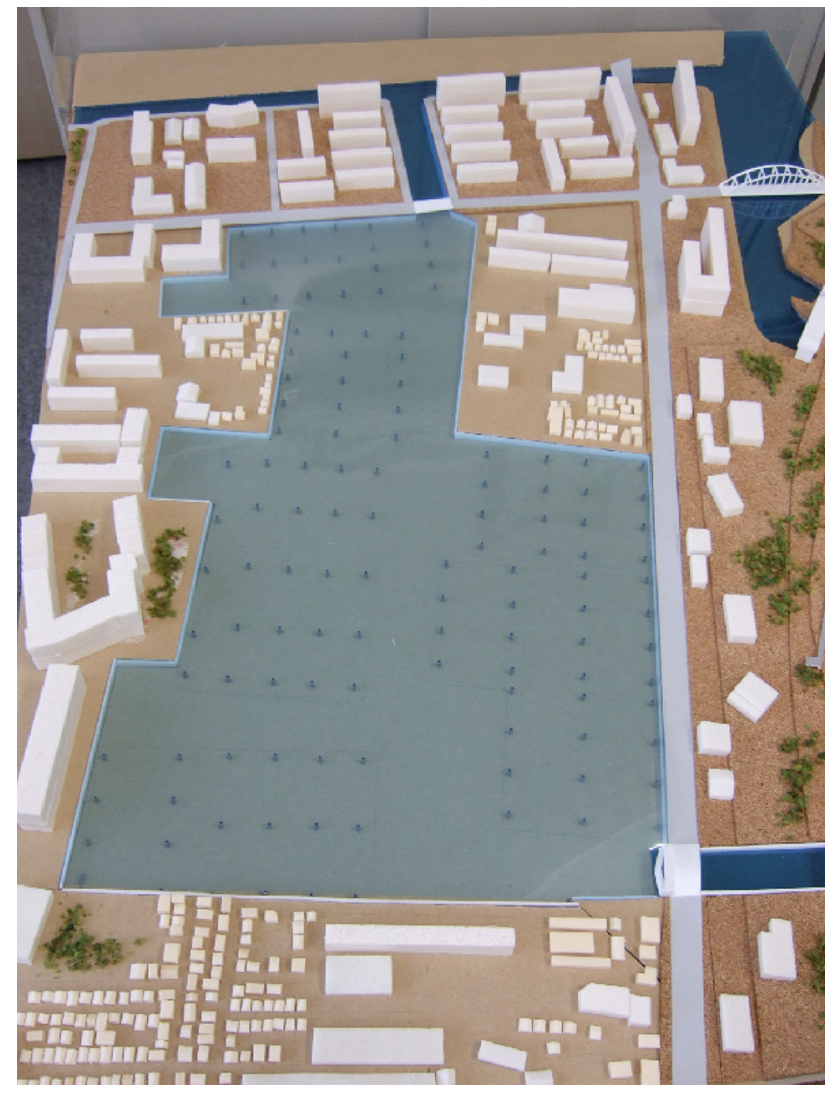

Fig. 5 Construction of man-made reservoir

low-lying land is approximately $185,000 \mathrm{~m}^{2}$. The removed topsoil is used to pile up earth in another location above the mean sea level, and this excavated area is filled with water. The man-made inlet and basin are constructed as shown in Fig. 5.

Second, floating foundations, consisting of many standard modular units, will be built inside the man-made basin (see Fig. 6). A total of 44 floating modular units are used in this water area over the total area of 11 ha. The steel bargetype floating foundation was chosen because of its outstanding performance in the Mega-float project conducted by the Mega-float Technological Research Association established by Japanese major shipbuilding companies during the 1990s. In this project, the length of a gigantic floating structure of $1,000 \mathrm{~m}$ was constructed and floated in Tokyo Bay. Many smaller floating modular units were combined and welded to one another on the sea surface, following a newly developed technique. Therefore, we aim to take advantage of the Megafloat project experiences, devices, and technologies (Nakajima et al. 2001). A single floating modular unit is designed to be $100 \mathrm{~m}$ long because most city blocks are about $100 \mathrm{~m}$ since this is considered to be a comfortable distance for people to walk. The unit width is fixed at $25 \mathrm{~m}$, so the modular unit can be built in mid- to small-scale shipbuilding docks,

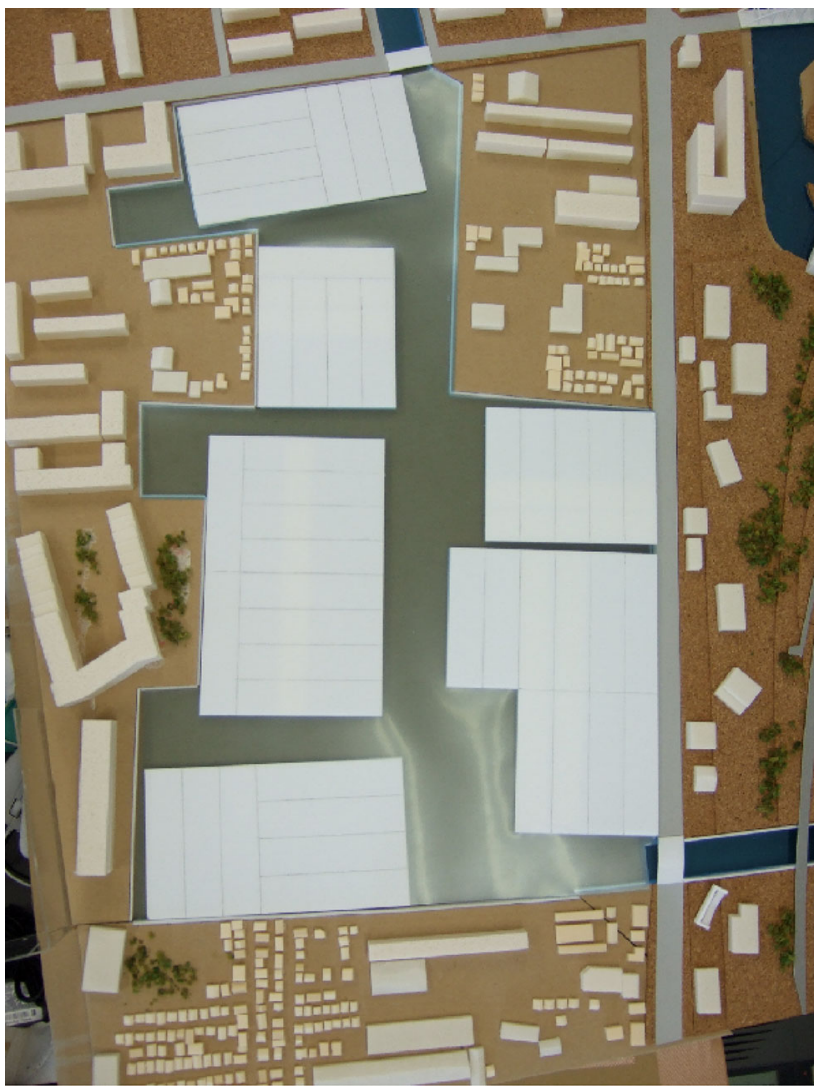

Fig. 6 Floating foundations on site in man-made reservoir

with the added advantage of being a divisor of 100 . The draft of the unit is $3.0 \mathrm{~m}$, while the height is $4.5 \mathrm{~m}$-these are the minimum dimensions of a car parking space. As for the floating modular units, by spreading them in horizontal directions, it is possible to form a town by adding more space as needed to meet future requirements. For a detailed practical design approach for very large floating structure, refer to Sato (2003).

Finally, as shown in Fig. 7, residential housing is constructed on floating foundations inside the man-made reservoir. We propose that pedestrian walkways be constructed around the man-made reservoir to create scenic areas where people can enjoy a picturesque waterfront. The urban heat problem caused by the accumulation of hot air will be alleviated by the natural cooling action of airflow over the water. This plan includes a waterway transportation system to enable passage among floating objects, canals, rivers, and the bay (see Fig. 8). The water surface level is designed to match that of the Onagi River, and the canals are located near this site to let boats travel between the man-made reservoir and river system. The floating foundation is designed to accommodate nearly 4,300 residents in 1,850 households with a population density of 390 persons/ha. 


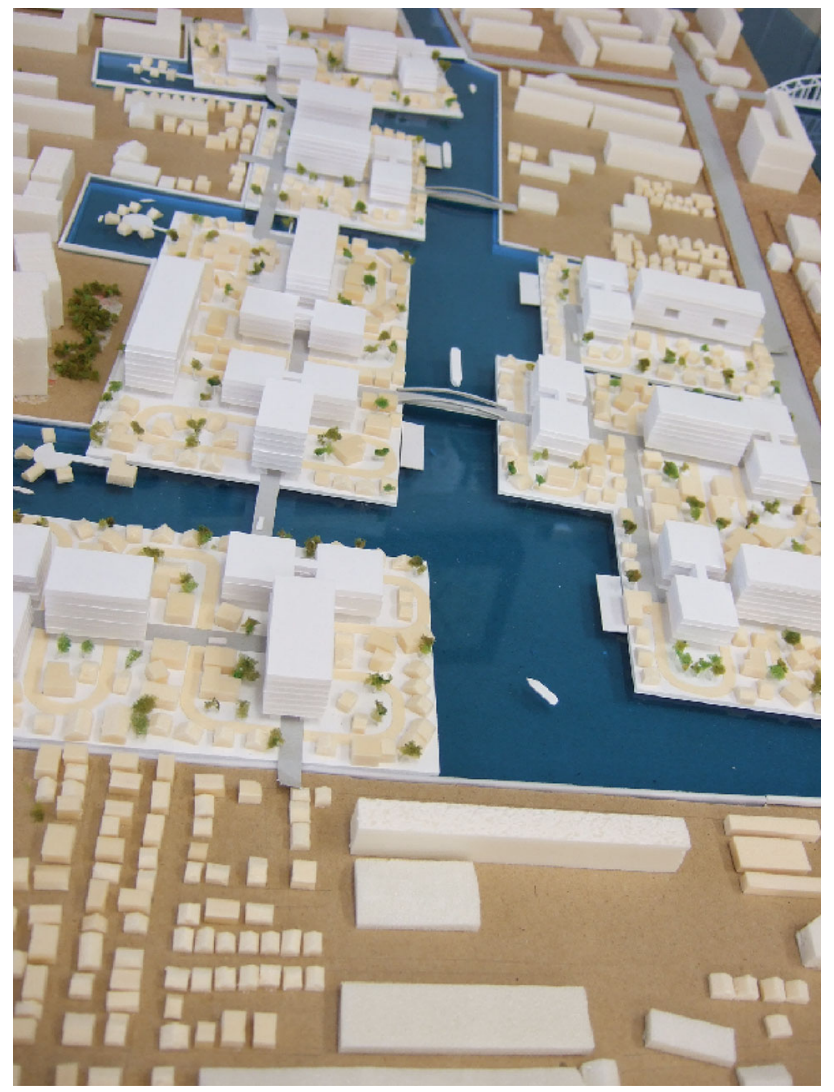

Fig. 7 Final plan view of the "Water City"

\subsection{Structural design of floating foundation and some engineering aspects}

Figure 9 shows the typical architectural structures on the floating foundation, consisting of 5 modular units $(100 \times$ $125 \mathrm{~m}$ ) while the principal dimensions are listed in Table 2. Several high-rise buildings with about 150 apartments and approximately 60 low-rise private houses can be built on the floating foundation with a buoyancy force of 37,500t (or $367,500 \mathrm{KN}$ ) including roads and open spaces. The information of floor areas and weights for the floating foundation is summarized in Table 3. The weight of $1 \mathrm{~m}^{2}$ of a reinforced concrete building for residential use was calculated to be $1.48 \mathrm{t} / \mathrm{m}^{2}$ in the fundamental study, and this value was used in the calculations. However, the value $0.167 \mathrm{t} / \mathrm{m}^{3}$ was used for the calculation of the approximate dead weight of a floating modular unit made of steel as estimated from data provided by the Mega-float project. Moreover, since this live load varies depending upon quantity, and materials, the design enables the adjustment of up to one-fifth of the total live load by regulating the volume of ballast water (the total volume of ballast water is $7,750 \mathrm{~m}^{3}$ ) inside the floating foundation.

In principle, as shown in Fig. 10, the floating foundation by itself is an example of the "soft landing system". In this

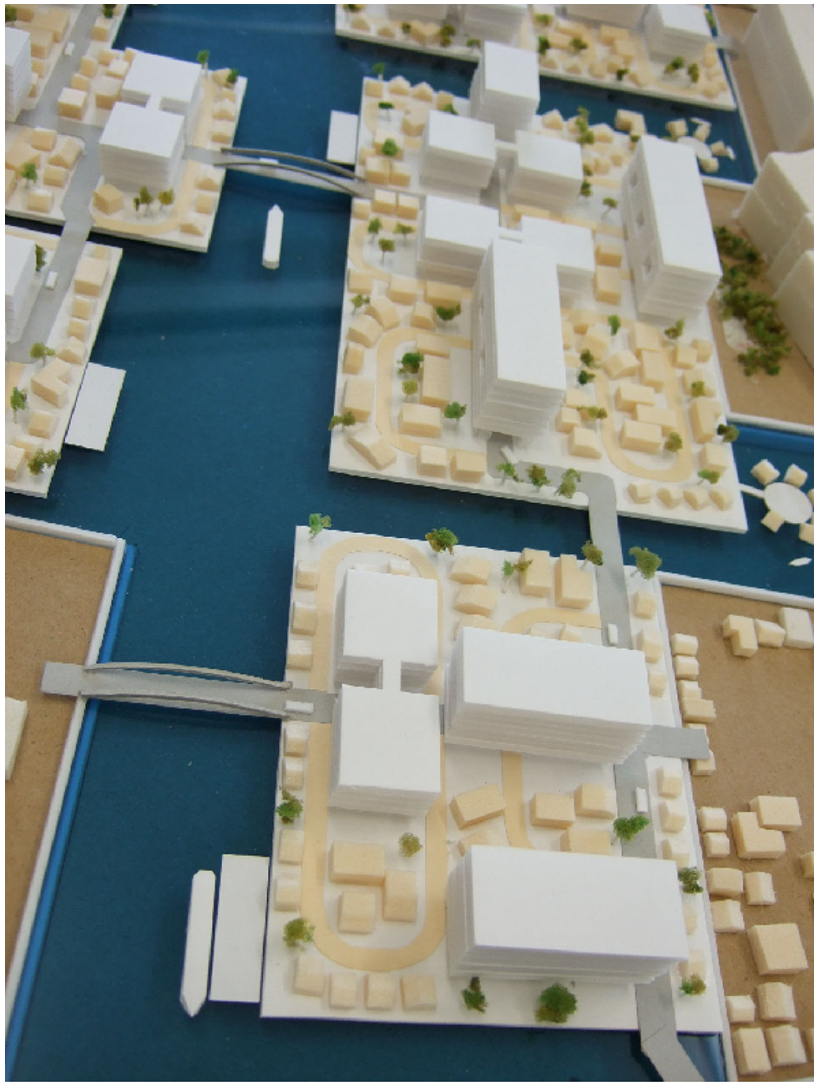

Fig. 8 Waterway transportation in "Water City"

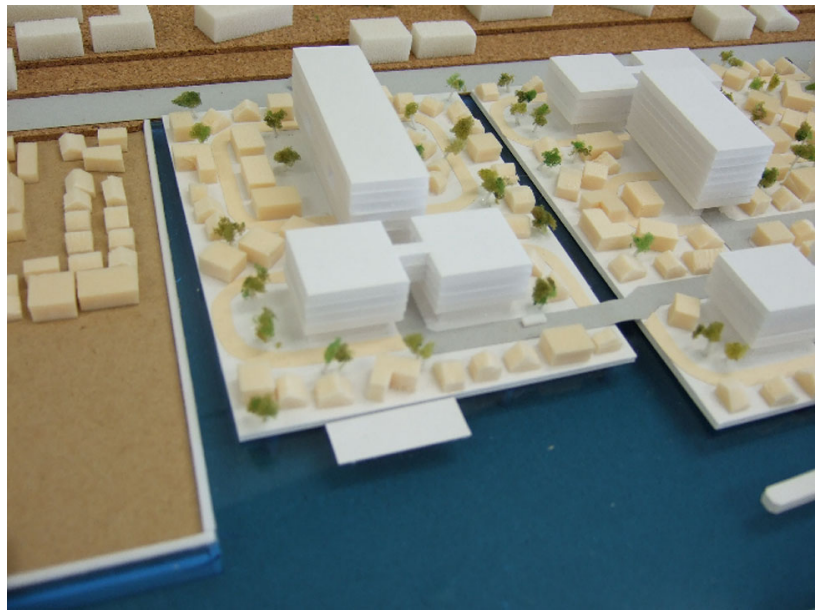

Fig. 9 Residential housings on floating foundation

Table 2 Principal dimensions of the floating foundation composed of five modular units

\begin{tabular}{llllll}
\hline Length & Width & Height & Draft & Displacement & Dead weight \\
\hline $125 \mathrm{~m}$ & $100 \mathrm{~m}$ & $4.5 \mathrm{~m}$ & $3.0 \mathrm{~m}$ & $37,500 \mathrm{t}$ & $9,400 \mathrm{t}$
\end{tabular}

system, a floating foundation is partially supported by concrete piles constructed underneath. The buoyancy provided by the floating foundation serves to lighten the load on the 
Table 3 Floor areas and weights of the floating foundation $(100 \mathrm{~m} \times 125 \mathrm{~m})$

\begin{tabular}{lcclll}
\hline & Floating foundation & Private houses & Apartment houses & Live loads & Ballast water \\
\hline Floor area in $\mathrm{m}^{2}$ & 12,500 & 7,200 & 11,600 & - & - \\
Weight in tons & 9,400 & 10,655 & 16,600 & 1,750 & 2,845 \\
\hline
\end{tabular}

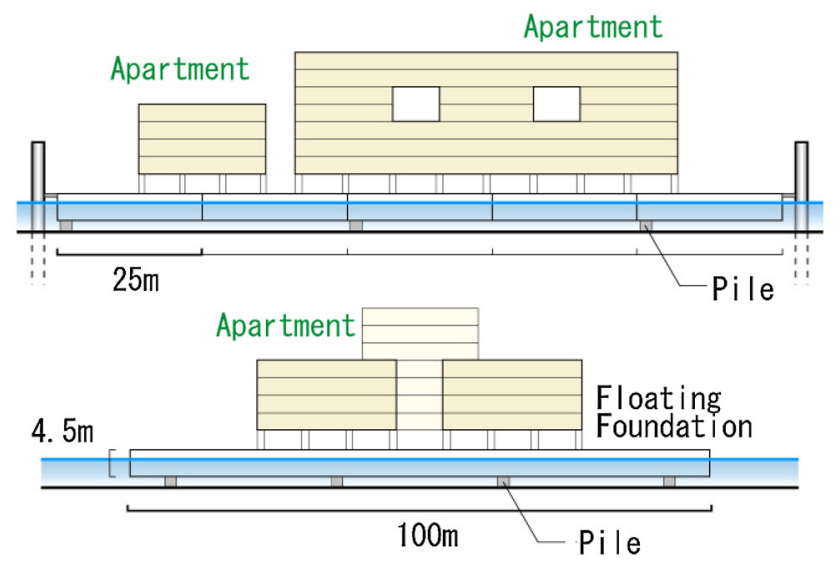

Fig. 10 Elevation view of the floating foundation

support piles. Laterally mounted support piles are connected to the floating foundation and have rubber fenders to control the horizontal excursion. Since approximately one-tenth of the total load is supported by several concrete piles, the final total load of the floating foundation is approximately $41,250 \mathrm{t}$ $(37,500 \mathrm{t}$ is supported by the buoyancy force of the floating foundation, while the piles support 3,750t). In case of an unexpected increase in water level because of the floodwater from heavy rains, the floating foundation can easily shift position up from the soft landed condition. In this case, the draft of the floating foundation becomes $3.3 \mathrm{~m}$ instead of 3.0 $\mathrm{m}$ when floating independently (see Fig. 11).

Because the floating foundation remains unaffected by open ocean water effects such as waves and tides, the main issue is earthquakes. However, floating foundations can be considered to be safer from earthquake damage than structures that stand directly on top of the ground. The floating unit used in this study minimizes the influence of earthquakes for two reasons. First, water serves to dampen the horizontal platform motion caused by earthquakes. Second, the natural period of vertical and horizontal platform motions becomes longer than those in air due to the increase in virtual mass of the platform in water. The result is that the tuning between the earthquake and platform motion is avoided.

The calculated vertical location of the center of gravity of the floating modular unit with buildings and ballast waters is $7.47 \mathrm{~m}$, while the calculated metacentric heights in the transverse and longitudinal directions for the floating foundation consisting of 5 floating modular units are 277.8 and $434.0 \mathrm{~m}$, respectively. These values indicate that the floating foundation is relatively stable against strong winds. In
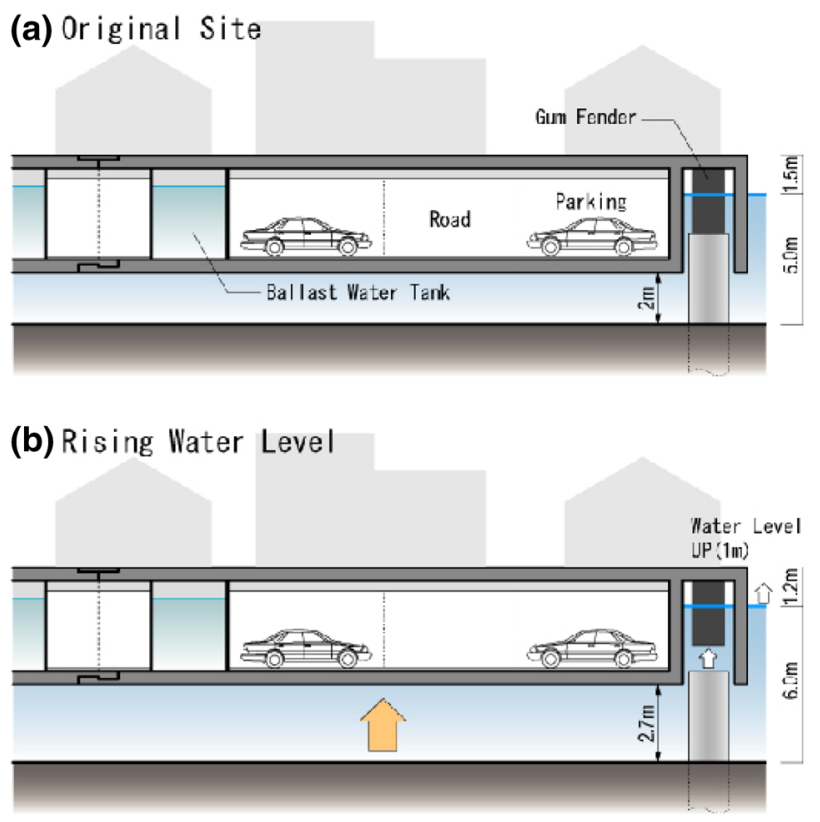

Fig. 11 Change in position of the floating foundation due to increasing water level

fact, the calculated heeling angles of the floating foundation, when considered from the maximum recorded wind speed of $39.6 \mathrm{~m} / \mathrm{s}$ during a storm in September of 1917, become $0.04^{\circ}$ in the transverse direction and $0.01^{\circ}$ in the longitudinal direction, thus showing that there is an extremely small effect generated because of strong winds.

\subsection{Economic point of view}

We also conducted an economic study for the construction of a "Water City," concentrating especially on the cost performance of a floating modular unit. To estimate the costs associated with the floating modular units, their economic efficiency was examined on the basis of the standard cash flow approach, and the asset value of the city on a floating unit was confirmed to be sufficiently high. The details are outlined in Nakajima and Umeyama (2010), and a summary of our economic analysis is as follows:

First, the cost for a floating modular unit built of steel was estimated using data from the Mega-float project; the cost was estimated to be 276,255 yen/t. Based on these estimations, the construction cost of a single floating modular unit $(100 \times 25 \mathrm{~m})$ for our research purpose will be approximately $519,400,000$ yen $(5,194,000$ dollars when the cur- 
rency exchange rate is $100 \mathrm{yen} /$ dollar). The total construction cost of housing and other structures on the floating unit will be $485,600,000$ yen. In addition, the cost for utility facilities and fixtures, such as water pipes, pumps, and electric cables, are estimated to be 200,000,000 yen. Hence, the combined total construction cost for buildings on a single floating modular unit is foreseen to be 1,205,000,000 yen. On the other hand, costs for construction of the reservoir will not be prohibitive; it is cheaper to excavate soil in low-lying lands at sea level because the quantity of soil to be removed is small.

Next, the simulation includes use of the space atop the floating unit as rental residences and retail establishments. The estimated capitalization return from parking, residences, and retail establishments will total to approximately $134,900,000$ yen/year. According to the standard cash flow approach, the overall appraisal is set at 2,698,000,000 yen and is more than double the total construction cost, which is calculated to be $1,205,000,000$ yen. Some economics studies show financial analyses indicating that waterfront urban residences based on floating units had more than enough asset value. Here, we emphasize that the economic standpoint for this scheme is completely different from that for conventional public works. Namely, construction is undertaken using private funds to build floating urban communities where the asset value rises along the waterfront; hence, it is possible to recoup the construction costs along the waterfront through usage fees after construction, in addition to the economic ripple effects emanating from this area. On the other hand, the construction costs for publicly funded levees are enormous and huge debts are incurred, and there is no possibility of making up the cost of construction, in sharp contrast to the development of floating urban communities offering a unique and economically attractive alternative.

\section{Application of present approach to rural coastal area}

\subsection{Construction scheme for rural coastal areas}

We also suggest applying the present concept to rural coastal areas for creating the so-called "Coastal Aqua-Villages" The plan is to replace these potentially dangerous sites into areas safeguarded against storm surges caused by huge typhoons, cyclones, and massive tsunamis. Figure 12a shows a typical dangerous situation of housing on coastal areas. The objective of this system is to introduce waterfront development for villages in coastal zones, such as the Maldives and Tuvalu, where the social infrastructure is built on floating foundations. Therefore, since these foundations will not submerge because of any rise in the water levels, this system provides a much safer and more comfortable living environment.

Under this scheme, a dangerous coastal zone area is excavated to a depth of several meters, and the topsoil is removed (a) Before removing soil

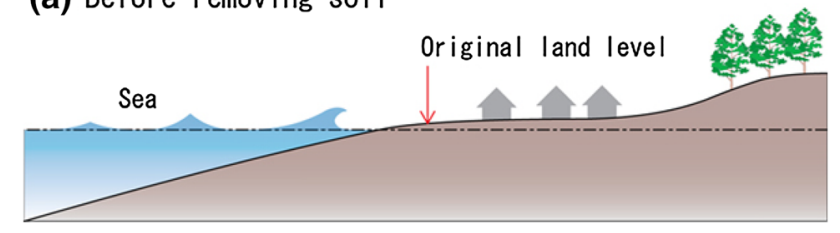

(b) After removing soil
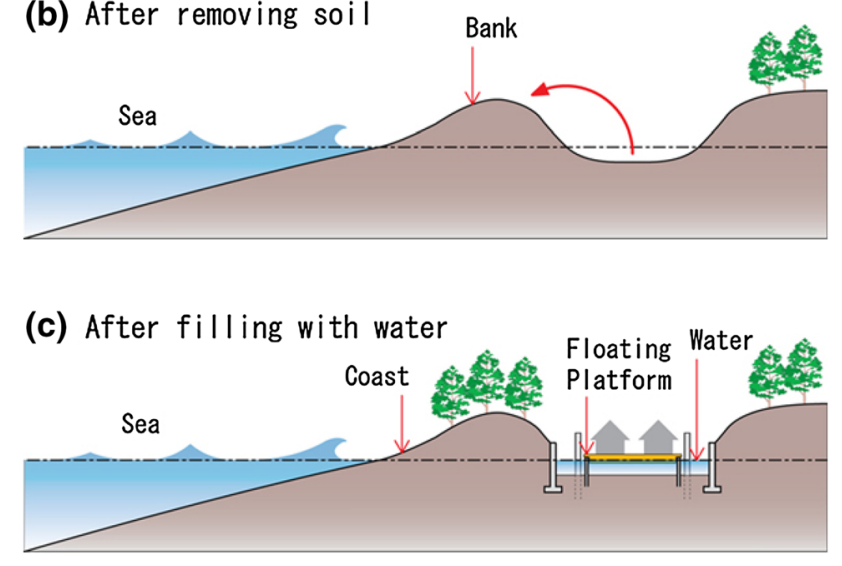

Fig. 12 Construction scheme for "Coastal Aqua-Villages"

from the site. The removed topsoil is then used to construct banks and hills at another area of the seaside site to protect against a run-up of seawater from storm surge and high waves (see Fig. 12b). Next, the man-made inlet or lagoon is filled with water, including saltwater, until the water surface reaches sea level. Finally, floaters made from lower cost materials such as lightweight concrete are distributed. Houses and even rice paddies agricultural fields are placed on floaters inside the man-made lagoon (see Fig. 12c). When there is an unexpected increase in water levels because of a high tide and floodwater from storm surges and tsunamis, the floater can easily shift its position to the soft landed condition. The plan view of this concept is illustrated in Fig. 13, while an artist's rendition of a "Coastal Aqua-Villages" is shown in Fig. 14.

\subsection{Master plan of "Coastal Aqua-Villages" for Arahama}

In 2011, a huge tsunami generated by a large earthquake at a hypocenter $160 \mathrm{~km}$ offshore from northeast Japan killed more than 15,000 residents and destroyed buildings and houses over a wide area near the shoreline. The world was shocked to learn that the maximum height of the tsunami waves surpassed $10 \mathrm{~m}$. Subsequently, especially around coastal areas, additional tall guide rail towers are planned be supported by floaters (see Fig. 15). One site extensively damaged by this tsunami, the Arahama area, is located on the coast of Miyagi Prefecture facing the Pacific Ocean. Many low-rise houses had been built in the rural residential area, surrounded by 


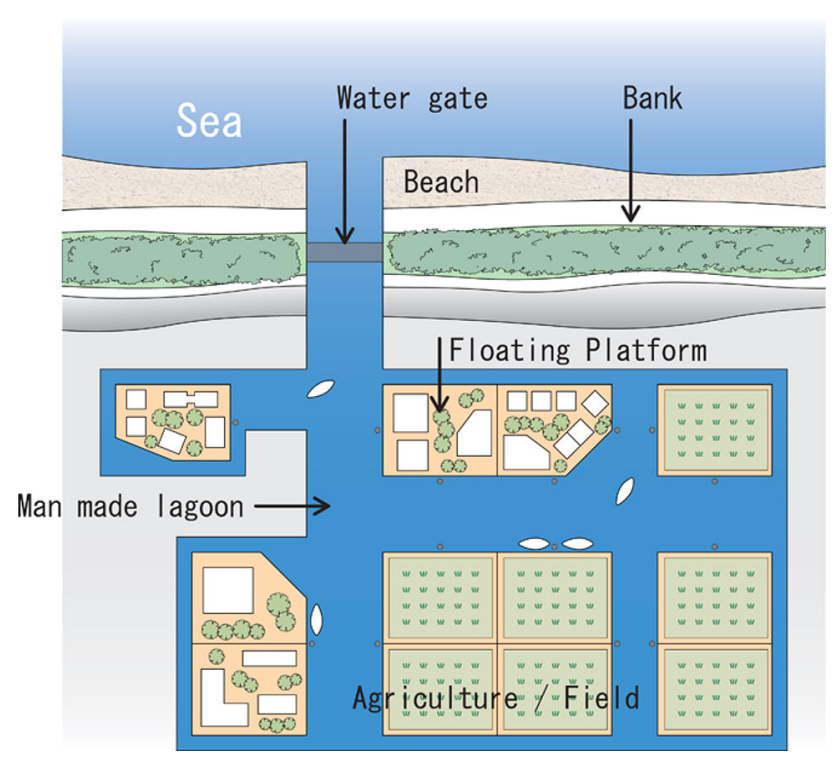

Fig. 13 Plan view of man-made lagoon with floaters

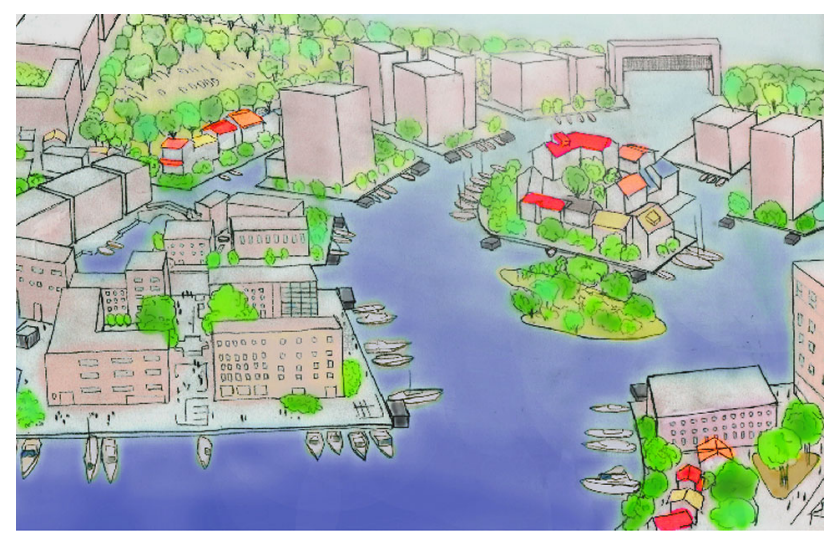

Fig. 14 Artist's rendition of "Coastal Aqua-Villages"

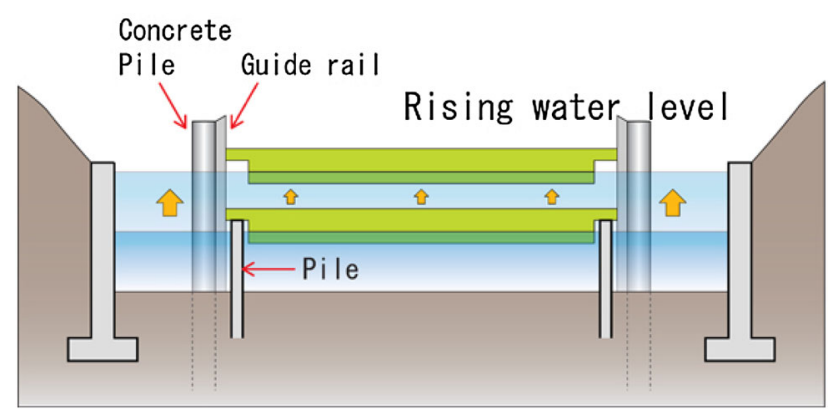

Fig. 15 Schematic elevation view of "soft landing system"

agricultural fields of rice. The population was about 2,700 people in 800 households. This area is located at almost the same latitude as the earthquake epicenter and is about $10 \mathrm{~km}$ southeast of the city center of Sendai (see Fig. 16). The Japanese media reported that Arahama was one of northeast Japan's most intensely damaged areas by the tsunami.

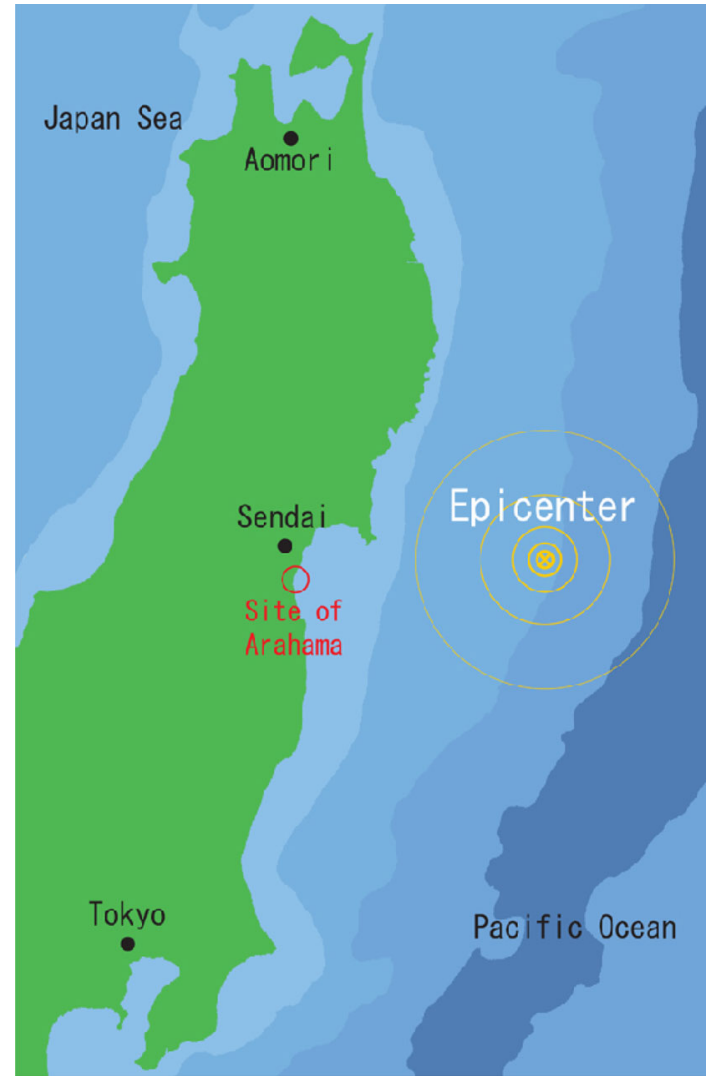

Fig. 16 Project site of Arahama area

The height of the tsunami wave was $9.38 \mathrm{~m}$ when it hit the Arahama area, and it extended about $4 \mathrm{~km}$ inland. The inundated area was approximately $13 \mathrm{~km}^{2}$. Hundreds of tsunami victims were found along this coastal area, and most of this region's houses up to $4 \mathrm{~km}$ inland were destroyed.

Therefore, the objective of this project is to introduce a waterfront development for coastal zone villages in the Arahama area. The social infrastructure is built on floating foundations that will not submerge due to any rise in the water levels (Nakajima et al. 2012). The ruined residential area of $800 \times 600 \mathrm{~m}$ is excavated, and the $0.0018 \mathrm{~km}^{3}$ of removed soil is used to construct higher banks surrounding the artificial water area. Next, the excavated area is filled with water to construct a man-made lagoon. Finally, floating platforms are distributed inside the man-made lagoon (see Fig. 17).

The man-made lagoon is constructed approximately 200$250 \mathrm{~m}$ from the coast line and is connected to the sea by 30 $\mathrm{m}$-wide channel used for water transportation. A 5-m-high water gate is constructed inside the channel, against the daily high tides, between the man-made lagoon and the sea. The Teizan Canal is also connected to the man-made lagoon. For access to the outside area, four public roads are connected with the floating roads that will serve as the structural frame. Pine trees are planted in the surrounding bank, with the height of bank to be $15-20 \mathrm{~m}$ in the coastal zone and $10 \mathrm{~m}$ in the 


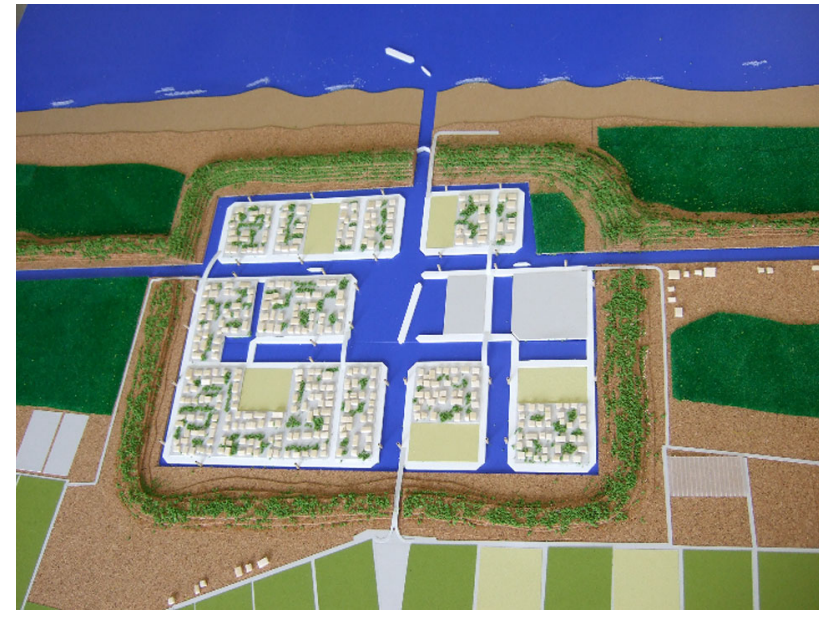

Fig. 17 Site plan of reconstruction for Arahama

inland zone. The total area of one floating platform will be $0.23 \mathrm{~km}^{2}$ for the $300-400$ low-rise houses and agricultural fields as shown in Fig. 17.

\section{Discussion and concluding remarks}

Many of the world's big cities are built on low-lying ground below sea level. These are potentially hazardous and riskprone locations with respect to natural disasters because of their proximity to seas and/or rivers. When torrential rainfall occur, gutters and sewer systems overflow, and rainwater overflows onto road systems. This sometimes results in massive damage and deaths. By thinking laterally, the weakness inherent in such locales locations can be transformed into their strength, whereby the water itself offers protection against water-related disasters. The idea presented in this paper is to construct buildings on floating foundations in calm man-made inlets or and basins rather than on land near seas and/or rivers.

The objective of this paper is to introduce a far-sighted project for waterfront development of a city area in lowlying ground (i.e., Koto Ward). In addition to waterfront redevelopment in high-density urban areas, another application of our concept is introduced for the reconstruction of the coastal area of Arahama, destroyed because of the tsunami caused by the Great East Japan Earthquake in northeast Japan (see Fig. 18). We believe that a similar coastal system works very well not only for this reconstruction scheme but is also applicable for isolated islands such as the Maldives and Tuvalu, which experience floods caused by global warming. The idea of constructing living spaces on floating foundations emanates from offshore technology reported by e.g., Ertekin and Riggs (2003), Yamashita et al. (2003), and Takai and Hoshino (1998). The application of these authors'

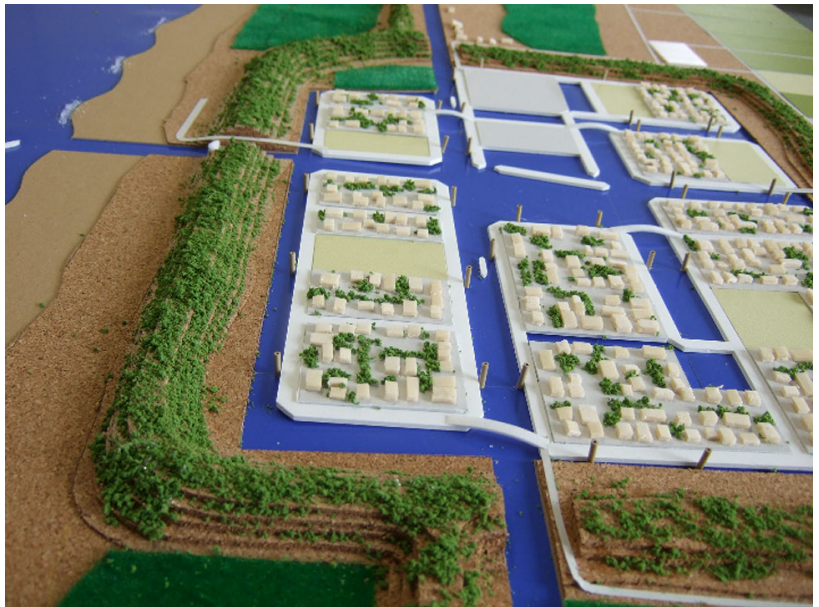

Fig. 18 Bird's-eye view of "Coastal Aqua-Villages" for Arahama

contributions for civil purposes, such as in very large floating structures, should be given very serious consideration. To realize a prosperous future, we strongly recommend that this offshore technology and knowledge about floating structures be applied to architecture and buildings on land. At the same time, to protect the global environment, there must be a shift from conventional tenets by actively promoting the use of renewable energy and fully replacing our energy systems to meet the present demands. Concurrent with this Smart Grid thrust for energy, there is a need for a policy shift for lowlying urban areas away from conventional urban expansion and renewal efforts to enable the realization of a truly sustainable urban system for the future in an innovative and strategic manner.

Acknowledgments The authors are grateful to Dr. Hironori Sugimoto, general manager of Marine Technology and Development Dept. at the Shipbuilding Research Centre of Japan, for disclosure of various practical data concerning with the Mega-float project for this paper.

\section{References}

Bender MA, Knutson TR, Tuleya RE, Sirutis JJ, Vecchi GA, Garner ST, Held IM (2010) Modeled impact of anthropogenic warming on the frequency of intense Atlantic hurricanes. Science 327(5964):454458. doi: $10.1126 /$ science. 1180568

Ertekin RC, Riggs HR (2003) Static and dynamic analyses of a moored causeway. In: Proceedings of 4th international symposium on ocean space utilization, National Maritime Research Institute, Tokyo, Japan, January 28-31, 2003, pp 91-100

Intergovernmental Panel on Climate Change (2014) IPCC fifth assessment report-climate change 2014. Intergovernmental Panel on Climate Change

Knutson TR, McBride JL, Chan J, Emanuel K, Holland G, Landsea C, Held I, Kossin JP, Srivastava AK, Sugi M (2010) Tropical cyclones and climate change. Nat Geosci 3(3):157-163. doi:10.1038/ngeo779

Nakajima T, Umeyama M (2007) A proposal for a floating urban communities in the man-made inlets. Proceedings of International symposium sustainable urban environment (ISSUE2007). Tokyo 
Metropolitan University, Graduate School of Urban Environmental Science, pp 27-33

Nakajima T, Umeyama M (2009) Floating Cities as a solution to the escalating sea level rise in lower-lying land areas. In: Proceedings of regional conference environment and earth resources, Malaysia, pp 261-269

Nakajima T, Umeyama M (2010) Study on a waterfront urban community in lower-lying land areas. Techno-Ocean (2010) international symposium, Kobe, CD-ROM

Nakajima T, Umeyama M (2013) Water City as solution to escalating sea level rise in lower-lying areas. Oceans '13, MTS/IEEE, San Diego, California, CD-ROM

Nakajima T, Iijima K, Inoue K, Inoue S, Kagemoto H, Hara S (2001) On the planning of a very large floating structure. 16th Ocean engineering symposium, Society of Naval Architecture of Japan, pp 221-228

Nakajima T, Shintani T, Umeyama M (2011) A new concept for lowerlying land areas and coastal villages safe from natural disasters. Oceans'11, MTS/IEEE Kona, Hawaii, CD-ROM

Nakajima T, Sugimoto H, Kawagishi U, Umeyama M (2012) A concept for water-based community to sea level rise in the lower-lying land areas-toward reconstruction of coastline area in disaster-stricken northeast Japan. Oceans '12, MTS/IEEE: Hampton Road, Virginia, CD-ROM
Sato C (2003) Result of 6 years research project of Mega-float. In: Proceedings of international symposium on ocean space utilization technology, National Maritime Research Institute, Tokyo, Japan, January 28-31, 2003, pp 436-442

Takai R, Hoshino K (1998) A consideration on the coefficient of friction drag and viscous damping of a Pontoon-type VLFS. In: 14th ocean engineering symposium. Society of Naval Architecture of Japan, pp $441-446$

Titus JG, Narayanan V (1995) The probability of sea level rise. EPA230R95-008, US Environmental Protection Agency, Washington, DC, p 186

Umeyama M (2012) Shore protection against sea level rise and tropical cyclones in small island states. Nat Hazards Rev ASCE 13(2):106116. doi:10.1061/(ASCE)NH.1527-6996.0000052

Yamashita Y, Yonezawa M, Shimamune S, Kinoshita Y (2003) Joining technology for construction of very large floating structures. In: Proceedings of 4th international symposium on ocean space utilization, National Maritime Research Institute, Tokyo, Japan, January 28-31, 2003, pp 229-237 